\title{
Programmable Multi-Functional RF/Microwave Circuit for Antenna and Filter Operation
}

\author{
A. L. Borja, Member, IEEE, Yasin Kabiri, and A. Belenguer, Senior Member, IEEE, J. R. Kelly, Member, IEEE
}

\begin{abstract}
This paper describes a multi-functional microwave device that can be reconfigured to behave either as a filter or an antenna. The device is based around a single resonant element, referred to as a building block element that is connected to 4 ports. The resonant element is a microstrip square patch working in the $2.45 \mathrm{GHz}$ unlicensed Industrial Scientific and Medical (ISM) band used for IEEE 802.11 WiFi. The proposed building block is simple in its design and construction. The paper also presents devices composed of three building blocks, which can realize more complex filtering and antenna mode performance. In addition, PIN diodes have also been incorporated into the devices in order to facilitate electronic control. Measured results, pertaining to fabricated prototypes, show that filter and antenna operation can be achieved, in the same device at a frequency of around $2.45 \mathrm{GHz}$ with acceptable insertion loss and efficiency. In the future, it is anticipated that this could lead to a new paradigm, namely a device that is analogous to a field programmable gate array (FPGA) operating in the microwave frequency regime.
\end{abstract}

Index Terms-Microwave antenna, microwave filter, programmable microwave function array, reconfigurable antenna, reconfigurable filter.

\section{INTRODUCTION AND MOTIVATION}

$\mathrm{T}$ HERE is increasing interest in reconfigurable antennas and circuits which are enabling technologies for the next generation of intelligent/self-aware systems. In communication systems, reconfigurable antennas/circuits are valuable to avoid and mitigate for spectrum congestion and interference. For numerous applications, including: small space satellites, and military communication systems, size and weight are important features that need to be minimised.

This paper introduces a multifunctional device, based on a single resonant element that can be reconfigured to operate as either a filter or an antenna. The single element is analogous to the configurable logic block (CLB) within an FPGA, and as such, it will be referred to as a building block element (BBE). An FPGA contains numerous CLBs which can be connected together, via programmable interconnect, in order to realise more complex circuit functions. Likewise, several instances of the BBE, proposed here, could be interconnected to obtain more complex microwave circuit functions. In this paper we

This work was supported by the Ministerio de Ciencia e Innovación, Spanish Government, under Research Projects TEC2016-75934-C4-3-R.

A. L. Borja and A. Belenguer are with Departamento de Ingeniería eléctrica, electrónica, automática y comunicaciones, Escuela Politécnica de Albacete, Campus Universitario, 02071 Albacete and Escuela Politécnica de Cuenca, Campus Universitario, 16071 Cuenca, Universidad de Castilla-La demonstrate, for the first time, a passive $\mathrm{RF} /$ Microwave device based around 3 BBEs. We show that the device can support multi-pole filter operation and also behave as an antenna. In the future, it is anticipated that this could lead to a new paradigm, namely a device that is analogous to a field programmable gate array (FPGA) operating in the microwave frequency regime.

\section{BACKGROUND LITERATURE REVIEW}

In recent years, a great effort has been devoted to the design of agile filters with tunable central frequencies [1]-[5] or bandwidth [6]-[11], as well as filters with the ability to switch their operating mode e.g. between bandpass and bandstop [12]-[14]. There is also a considerable body of work on versatile antennas with tunable working frequency [15]-[19], radiation pattern shape [20]-[22], and polarization [23]-[25]. It is worth mentioning that all of the aforementioned designs afford only a single circuit function (i.e. filter only or antenna only). There is therefore a need for a new class of $\mathrm{RF} /$ microwave multi-functional devices that extend the advantages of tunable devices. Some devices of this nature have been demonstrated either using active or passive components [26]-[34]. At this point, it is worth noting that a variety of different terminology is used in reference to this type of device, including: PROgrammable MicroWave Function Array (PROMFA), reconfigurable microwave components, programmable and tunable circuits, adaptable RF systems, multi-functional RF systems, multi-functional microwave circuits. There is relative lack of work on multifunctional microwave devices based on passive components, although the work conducted to date demonstrates an extensive range of potential applications and benefits compared to conventional devices. For example, a multifunctional microwave device could: update its function in response to changes in operational requirements, reconfigure its operation in order to anticipate changes in user demand, yield improved environmental sustainability, and reduce the cost, size, and time associated with the hardware development cycle.

In this paper we have chosen to focus our efforts in the area of passive microwave circuits, building on our earlier work [35]-[38]. Specifically, our objective was to reuse the same

\footnotetext{
Mancha, Spain (e-mail: alejandro.lucas@uclm.es; angel.belenguer@uclm.es;).

J. R. Kelly and Yasin Kabiri are with the Centre for Communication Systems Research, University of Surrey, GU2 7XH Guildford, U.K. (e-mail: j.r.kelly@surrey.ac.uk).
} 
volume of space within a circuit to achieve two different functions, namely antenna and filter operation. The main advantages of the proposed BBE, compared to previous work, is the simplicity of the design along with the ability to electronically control the operating mode.

The paper is organized as follows: Section III describes the concept and design procedure for the BBE. It also analyses the effect of the choice of substrate permittivity on the performance of the device and presents a device incorporating 3 BBEs. Section IV discusses simulation and measurement results pertaining to a range of designs, incorporating 1 and 3 BBEs. Section V outlines the conclusions of the work.

\section{CONCEPT AND DESIGN}

\section{A. Building Block Element (BBE),}

This subsection of the paper describes the concept behind the design of the BBE. It also details the geometry and dimensions employed. The primary objective, in designing the $\mathrm{BBE}$, was to conceive of a structure of the device that would allow a single resonator to service two different circuit functions (namely filtering and radiation); thus, yielding space saving advantages. A secondary objective was to find the simplest possible solution. Two main approaches were available: 1) excite two independent (isolated) characteristic basis modes within the resonator. Each mode would be excited via a different feed excitation. One mode would be used for the filter operation whilst the other would be used for antenna operation [35]-[36], 2) excite a pair of coupled characteristic basis modes within the resonator and use switches to vary the mode that is excited at any one instance of time. We chose to adopt the latter approach in this paper.

Fig. 1 illustrates the structure of the BBE along with the associated dimensions. The substrate material was Rogers 4003 , having a relative permittivity of 3.55 and a thickness of $1.524 \mathrm{~mm}$. This material was used in the fabrication of all of the prototype designs presented in this paper.

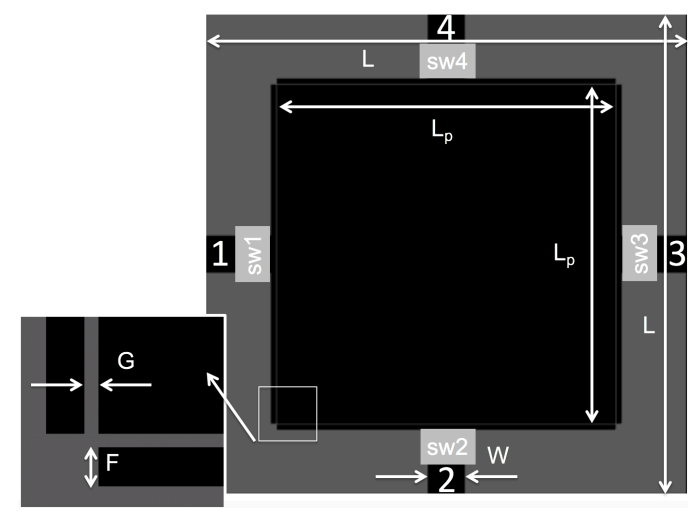

Fig. 1. Structure of the building block element. $\mathrm{L}=45 \mathrm{~mm}, \mathrm{Lp}=31.6$ $\mathrm{mm}, \mathrm{W}=3.36 \mathrm{~mm}, \mathrm{~F}=0.4 \mathrm{~mm}$ and $\mathrm{G}=0.15 \mathrm{~mm}$.

The BBE is based around a square microstrip patch resonator. The resonator is surrounded by four microstrip feedlines that have been designed to exhibit a characteristic impedance of $50 \Omega$. Electromagnetic energy is coupled from the microstrip lines into the square patch through a narrow gap, denoted $G$ (see inset in Fig. 1). A single microwave switch (indicated by the grey block in Fig. 1) is placed within each of the microstrip feedlines. By altering the state of the four switches, within the device, it is possible to reconfigure between filter and antenna operation (see Table I).

TABLE I OPERATING MODES OF THE BUILDING BLOCK ELEMENT

\begin{tabular}{ccccc}
\hline \hline & Function & Ports & SW 1, 2, 3, 4 & Pol. \\
\hline Mode 1 & Filter & 1 and 3 & on, off, on, off & - \\
Mode 2 & Filter & 2 and 4 & off, on, off, on & - \\
Mode 3 & Antenna & 1 or 3 & $\begin{array}{l}\text { on, off, off, off } \\
\text { off, off, on, off }\end{array}$ & H \\
Mode 4 & Antenna & 2 or 4 & $\begin{array}{l}\text { off, on, off, off } \\
\text { off, off, off, on }\end{array}$ & V \\
\hline \hline
\end{tabular}

The BBE supports two filter modes and two antenna modes, as indicated in Table I. Modes 1 and 2 afford filter operation between ports 1 and 3, or 2 and 4, respectively. Modes 3 and 4 offer antenna operation on each of the four ports. The different antenna modes yield different states of linear polarization (i.e. vertical or horizontal). For the purpose of this proof-of-concept design, the filter and antenna modes of operation are configured to suit a real application, namely WiFi devices, operating within unlicensed Industrial Scientific and Medical (ISM) band at a frequency of 2.45 $\mathrm{GHz}$. During the initial stages of the research, the design for the BBE was validated using hard-wired switches. According to this approach, an on-state switch is represented by copper metallization, whilst an off-state switch is represented by the absence of copper metallization (i.e. a gap).

\section{B. Design Rules}

This subsection of the paper presents information that can be used to redesign the BBE, e.g. for operation at a different frequency. The process is simple due to the simplicity of the BBE. The design procedure can be summarized as follows:

1. Select the working frequency of the BBE. The length and width of the microstrip patch is then fixed to $L_{P}=\lambda / 2$.

2. The width (W) of the microstrip feedlines are set to ensure that they exhibit an impedance of $50 \Omega$.

3. The dimension of the gap into which the switches are placed should be wide enough to provide an isolation, in the off-state, of at least $-25 \mathrm{~dB}$.

4. Finally, the dimensions $\mathrm{G}$ and $\mathrm{F}$ are selected by means of parametric analysis to achieve strong coupling and good matching between the microstrip line and the square patch, in both filter and antenna modes. 


\section{Choice of Substrate Parameters}

In the BBE, shown in Fig. 1, a single resonator is employed to achieve filter and antenna mode operation, as mentioned earlier. The switches effectively repurpose the resonator so that it can be used for different circuit functions. However, the requirements of an antenna are quite different to those of a filter. In a planar microstrip filter, the electric field should be mainly confined within the substrate material and very little electromagnetic energy should be radiated from the device. For an antenna, on the other hand, the electric field will be less confined within the substrate material and the majority of the energy supplied to the device should emerge in the form of radiated electromagnetic waves. For this reason, it was anticipated that there might be an engineering trade-off to be made when selecting the parameters of the substrate material. To investigate this, the effect of the substrate height and permittivity were analyzed against important performance criteria (namely the total efficiency of the antenna and the insertion loss within the pass band of the filter). Figs. 2 and 3 show the results.

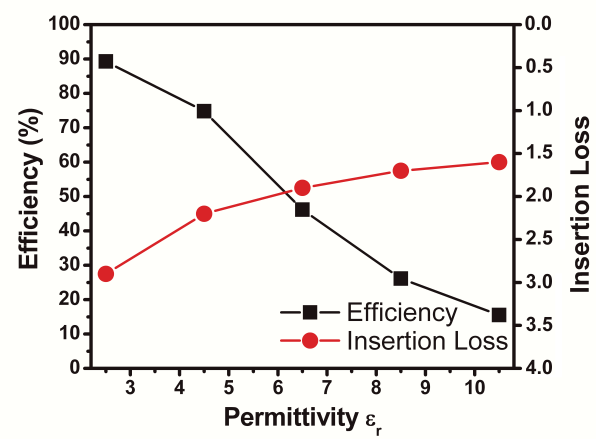

Fig. 2. Antenna total efficiency and filter insertion loss as a function of substrate relative permittivity.

TABLE II

SUBSTRATE PERMITIVITY PARAMETRIC STUDY

\begin{tabular}{ccc}
$\varepsilon_{\mathrm{r}}$ & Total Efficiency $(\%)$ & Insertion Loss $(\mathrm{dB})$ \\
\hline 2.5 & 89.3 & -2.9 \\
4.5 & 74.8 & -2.2 \\
6.5 & 46.2 & -1.9 \\
8.5 & 26.1 & -1.7 \\
10.5 & 15.5 & -1.6 \\
\hline \hline
\end{tabular}

For convenience, Tables II and III give the numerical values, used to plot Figs. 2 and 3. We can make a number of observations on inspection of Fig. 2 and Table II. For the antenna mode of operation, the total efficiency attains a maximum value for low values of substrate permittivity and it reduces, from around $90 \%$, as the permittivity is increased. This finding concurs with text book theory [40]. For the filter mode of operation, the insertion loss reduces asymptotically from $-3 \mathrm{~dB}$ as the substrate permittivity is increased. The explanation for this is that when the substrate permittivity is high the electric field is predominantly confined within the substrate. This leads to increased levels of stored energy and reduced radiation which is conducive with achieving good filter performance. Contrariwise, when the substrate permittivity is low the electric field is more equally distributed between the air region, beneath the microstrip patch, and the air region above the patch. This reduces the level of stored energy and leads to greater radiation, as is desirable for an antenna.

Fig. 3 shows antenna total efficiency along with filter insertion loss as a function of the substrate height. From Fig. 3 we see that increasing the substrate height leads to an asymptotic improvement of the antenna total efficiency and a reduction of the filter insertion loss. The optimum substrate thickness is around $1.5 \mathrm{~mm}$, which yields an antenna total efficiency of $84 \%$ and a filter insertion loss of $2.5 \mathrm{~dB}$. Further increasing the substrate height has limited effect due to the asymptotic relationship, mentioned earlier. For our proof-ofconcept design we decided to target a filter insertion loss of around $2.5 \mathrm{~dB}$ and an antenna efficiency of between $75 \%$ and $80 \%$. Consequently, a substrate material with permittivity of 3.55 and a height of $1.524 \mathrm{~mm}$ was selected.

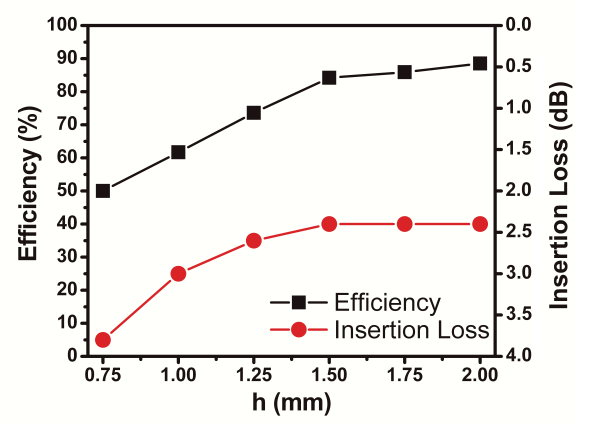

Fig. 3. Antenna total efficiency and filter insertion loss as a function of substrate thickness.

TABLE III

SUBSTRATE THICKNESS PARAMETRIC STUDY

\begin{tabular}{ccc}
$\mathrm{h}(\mathrm{mm})$ & Efficiency $(\%)$ & Insertion Loss $(\mathrm{dB})$ \\
\hline 0.75 & 50.0 & -3.8 \\
1.00 & 61.7 & -3.0 \\
1.25 & 73.6 & -2.6 \\
1.50 & 84.2 & -2.4 \\
1.75 & 85.9 & -2.4 \\
2.00 & 88.5 & -2.4 \\
\hline \hline
\end{tabular}

One can thus conclude that the device performance can be modified by altering the substrate parameters. For instance, substrates with high permittivity and low or moderate thickness are the most appropriate for filter applications, whereas substrates with low permittivity and high thickness are most optimal for antenna applications. In this way, single function devices can be optimized for filter or antenna operation and will thus present good insertion or return losses, respectively. The requirements of an antenna are almost opposite to those of a filter in that the former should ideally radiate strongly whilst the latter should ideally not radiate at all. The creation of a multi-functional device thus implies a compromise (or trade-off) between the filter and antenna performance that degrades both the insertion loss for the filter mode and the return loss/efficiency for the antenna mode in 
exchange for having the flexibility to repurpose the hardware to perform either function.

\section{Device Comprising Three BBEs}

This subsection of the paper presents the design of a 3-pole filter based around the BBE, presented in Section A. The filter has been designed using the well-known insertion loss method [39]. The substrate material was Rogers 4003, having a relative permittivity of 3.55 and a thickness $1.524 \mathrm{~mm}$. The specifications of the filter are as follows:

Filter characteristic:

Chebyshev

Fractional bandwidth (FBW):

$8.16 \%$

Centre frequency:

$2.45 \mathrm{GHz}$

Passband ripple:

$0.1 \mathrm{~dB}$

The lumped circuit elements, within the low-pass prototype, were impedance and frequency scaled, according to the standard approach [39]. Next, a low-pass to band-pass transformation is applied [39]. To enable filter implementation in microstrip technology, the shunt connected parallel resonators were realized using microstrip patches. An admittance inverter can be represented using a $\pi$-network of three lumped capacitors. The same $\pi$-network can be used to model the behavior of a gap between two microstrip transmission lines. Consequently, we can replace the admittance inverter with a capacitive gap between the microstrip patch resonators. In order to establish the necessary equivalence, the size of each capacitive gap was varied iteratively until its scattering-parameters agreed with those for of the admittance inverter that we wished to realize. Fig. 4 illustrates the final geometry of the device incorporating 3 BBEs.

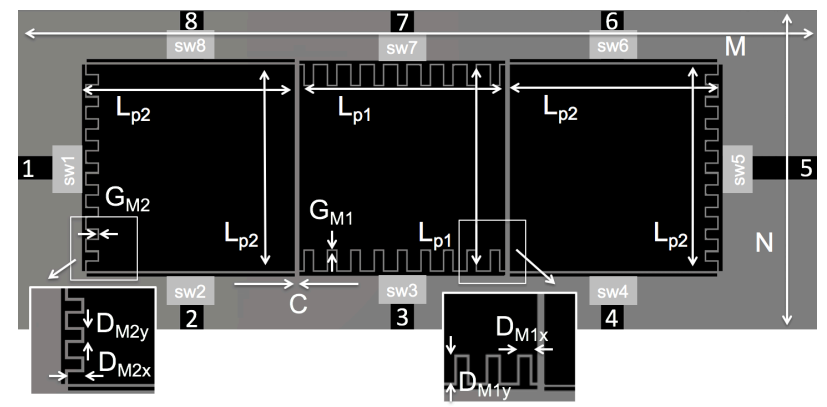

Fig. 4. Geometry of the device incorporating 3 building block elements. $\mathrm{M}=124.6, \mathrm{~N}=61, \mathrm{~L}_{\mathrm{p} 1}=30.8, \mathrm{~L}_{\mathrm{p} 2}=31.1, \mathrm{~F}_{1}=\mathrm{F}_{2}=0.4, \mathrm{G}_{\mathrm{M} 1}=0.085, \mathrm{G}_{2}=0.1$, $\mathrm{G}_{\mathrm{M} 2}=0.15, \mathrm{C}=0.7, \mathrm{D}_{\mathrm{M} 1 \mathrm{x}}=\mathrm{D}_{\mathrm{M} 1 \mathrm{y}}=0.425, \mathrm{D}_{\mathrm{M} 2 \mathrm{x}}=0.5$ and $\mathrm{D}_{\mathrm{M} 2 \mathrm{y}}=0.765$. All dimensions in $\mathrm{mm}$.

The device is symmetrical and incorporates three different designs of capacitive coupling gap. A meandered gap was employed in those cases where a high coupling coefficient is required. Two different designs of meandered gap were used within the device shown in Fig. 4. One of the meandered gap designs incorporates 34 meanders and has a gap width of $\mathrm{G}_{\mathrm{M} 1}=0.085 \mathrm{~mm}$. The other meandered gap design incorporates 32 meanders and has a gap width of $\mathrm{G}_{\mathrm{M} 2}=0.15 \mathrm{~mm}$, see inset of Fig. 2. The device can operate in five different modes, see Table IV. Mode 1 provides bandpass filter operation between ports 1 and 5 . In modes 2 to 5 the device behaves as a linearly polarized antenna having either horizontal or vertical polarization. Modes 2 and 5 yield a beam at boresight while modes 3 and 4 yield tilted beams.

TABLE IV

\begin{tabular}{ccccc} 
OPERATING MODES OF THE THREE BUILDING BLOCK ARRAY \\
\hline \hline Function & Ports & $\begin{array}{r}\text { SW 1, 2, 3, 4 } \\
\mathbf{5 , 6 , 7 , 8}\end{array}$ & Pol. \\
\hline Mode 1 & Filter & 1 and 5 & $\begin{array}{l}\text { on, off, off, off } \\
\text { on, off, off, off }\end{array}$ & - \\
Mode 2 & Antenna & 3 (or 7) & $\begin{array}{l}\text { off, off, on, off } \\
\text { off, off, off, off }\end{array}$ & V \\
Mode 3 & Antenna & 2 (or 6) & $\begin{array}{l}\text { off, on, off, off } \\
\text { off, off, off, off }\end{array}$ & V \\
Mode 4 & Antenna & 4 (or 8) & $\begin{array}{l}\text { off, off, off, on } \\
\text { off, off, off, off }\end{array}$ & V \\
Mode 5 & Antenna & 1 (or 5) & $\begin{array}{l}\text { on, on, off, off } \\
\text { off, off, off, off }\end{array}$ & H \\
\hline \hline
\end{tabular}

\section{Simulated And Measured Results}

This section of the paper presents results that validate the performance of the proposed BBE. All of the full-wave electromagnetic simulation results, presented in this paper, were obtained using the frequency domain Solver in CST Microwave Studio 2015. SMA connectors, substrate and metal losses were considered in all of the simulations. Where PIN diodes are employed, they have been modelled using lumped element equivalent circuits, obtained from the manufacturers webpage. All of the experimental results, presented in this section were obtained using either an Anritsu MS4642A or a Rohde and Schwarz ZVA67 Vector Network Analyzer (VNA), calibrated using the Through-Open-Short method.

\section{A. Single Hard-Wired BBE}

Fig. 5 shows hardware prototypes of the single BBE, shown in Fig. 1. These prototype devices incorporate hard-wired switches.

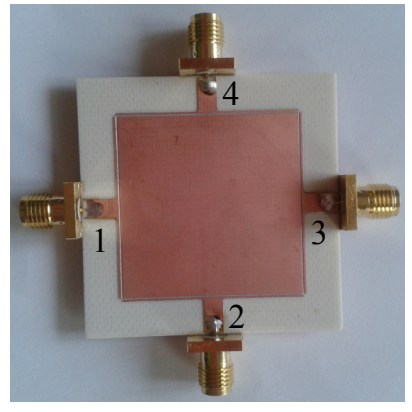

a)

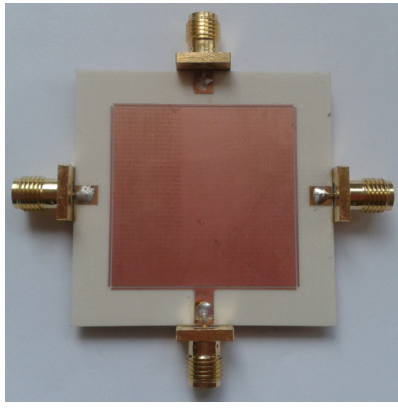

b)
Fig. 5. Hard-wired devices operating in: a) filter mode, b) antenna mode.

The device shown in Fig. 5 a) is configured to operate in the filter mode. In this prototype device, filter mode performance 
is obtained by bridging all four switch gaps with a copper conductor. In this way, it is possible to obtain filter mode performance simultaneously between ports 1 and 3 as well as ports 2 and 4. The second device, shown in Fig. 5 b), is configured to operate in the antenna mode with vertical polarization. Fig. 6 shows scattering parameters, obtained through simulation and measurement, for these devices. An excellent level of agreement can be observed between the simulation and measurement results. When configured for operation in the filter mode the device operates at a frequency of $2.41 \mathrm{GHz}$. The measured return and insertion loss values are $12.3 \mathrm{~dB}$ and $2.8 \mathrm{~dB}$, respectively. The filter has a measured $10 \mathrm{~dB}$ return loss bandwidth of $1.6 \%$ (i.e. $38 \mathrm{MHz}$ ). When configured for operation in the antenna mode the device operates at a frequency of $2.42 \mathrm{GHz}$. The measured return loss, at the resonant frequency, is $34.2 \mathrm{~dB}$.

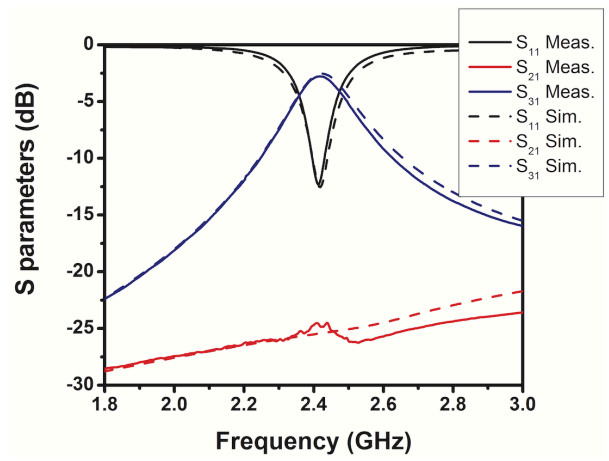

a)

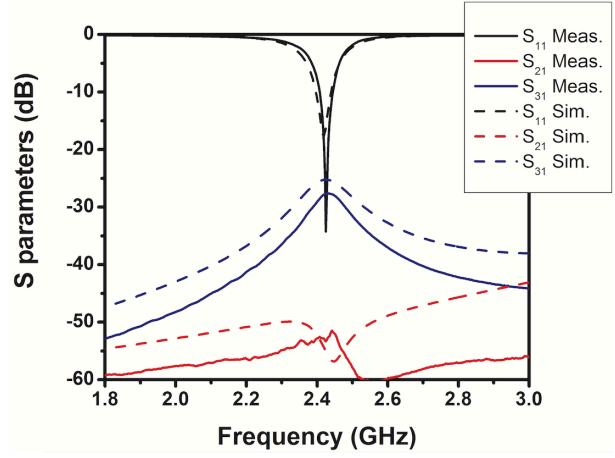

b)

Fig. 6. Scattering parameters for: a) filter mode, b) antenna mode.

According to the simulations the antenna exhibits a total efficiency of $83.1 \%$ and its peak gain is $5.23 \mathrm{dBi}$. It is undesirable for the BBE to radiate when operating in the filter mode. To assess this, radiation patterns for the filter mode were obtained through measurement. The H-plane gain, in the filter mode, is approximately $1.6 \mathrm{~dB}$ lower than that in the antenna mode. Whilst the E-plane gain, in the filter mode, is approximately $2.5 \mathrm{~dB}$ lower than that in the antenna mode. This indicates a reasonable discrimination between filter and antenna mode operation. Although the realized gain for the filter mode is always a positive value it is important to note that the peak gain associated with the filter mode is always lower than that associated with the antenna mode, as noted above. So, one might reasonably ask, what prevents us from being able to enhance the difference in realized gain between filter and antenna mode operation. Let us now explore this question further; considering, for clarify, filter mode operation between ports 1 and 3 and antenna mode operation on port 1 . The BBE, reported in this paper, is based around a square patch resonator. The method of excitation associated with the filter and antenna modes are essentially identical. Given these facts, the characteristic basis modes associated with filter operation between ports 1 and 3 , and antenna operation on port 1 are essentially identical, see Fig. 7. The only difference between the two modes of device operation is that the filter is a 2-port device whereas the antenna is a 1 port device. Hence, due to a conservation of energy argument, improving the $S_{21}$ for the filter mode has the desirable effect of "sucking" energy out of the device and thus reducing the level of radiation from the device. Increased radiation within the filter mode of operation is undesirable because it degrades the filter insertion loss. But it is a result of having better conditions for radiation which will lead to improved efficiency in the antenna mode. Thus, we see that there is a need to compromise between the insertion loss associated with filter operation and the return loss/efficiency associated with antenna performance, as mentioned before. For this reason, in a multi-functional device, it is not possible to further enhance the difference between the realized gain for the filter and antenna modes of operation without loss of performance in both modes.

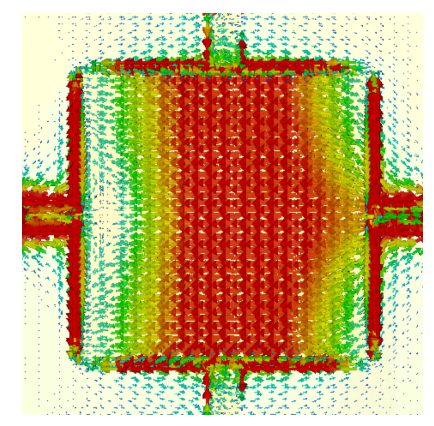

(a)

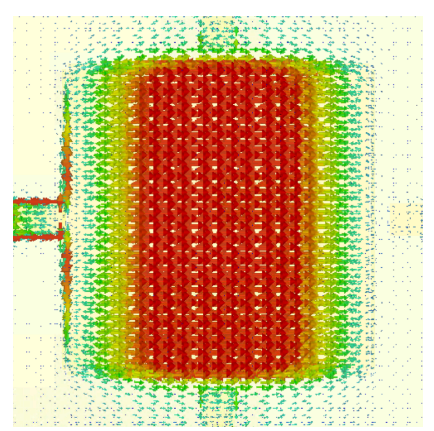

(b)
Fig. 7. Characteristic basis modes for $1 \mathrm{BBE}$ device. (a) operating in the filter mode between ports 1 and 3, (b) operating in the antenna mode on port 1 .

In both filter and antenna modes of operation, it is undesirable for energy to be transferred to unused ports of the device. The maximum level of such undesirable energy transfer, measured between adjacent ports was $-24.2 \mathrm{~dB}$ for filter operation and $-27.6 \mathrm{~dB}$ for antenna operation, respectively.

For the antenna mode of operation, the radiation patterns in the E- and H-planes are shown in Fig. 8. The radiation patterns are typical of those associated with a microstrip patch antenna. This indicates that the device performs in a predictable manner. The cross-polar radiation patterns have much smaller peak amplitudes than the co-polar patterns (more than $17.5 \mathrm{~dB}$ lower). This gives some indication of the level of isolation between the orthogonal characteristic basis modes that provide filter mode operation between ports 1 and 3 and antenna mode operation on port 2. 


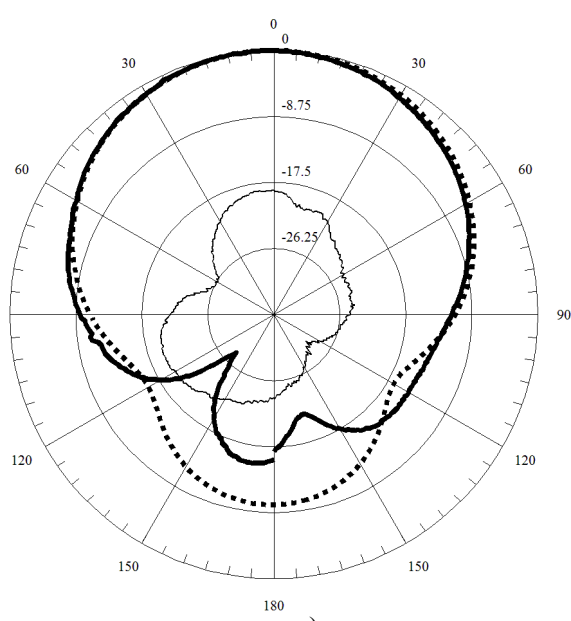

a)

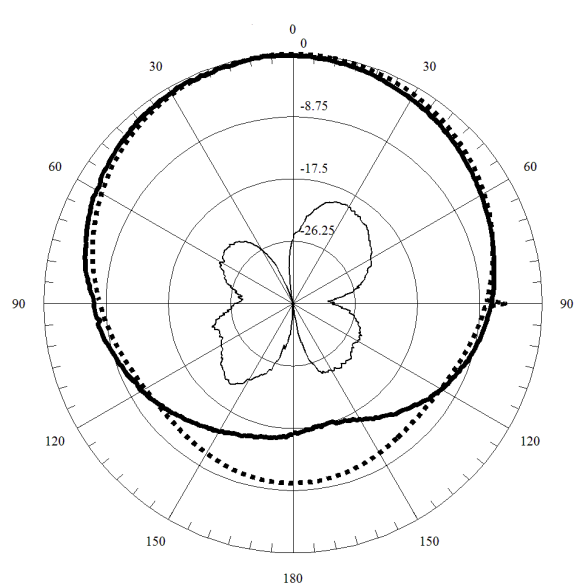

b)

Fig. 8. Radiation patterns: a) E-plane, and b) H-plane. Solid line, dashed line, and thin solid line, represent measured co-polar, simulated co-polar, and measured cross-polar, respectively.

\section{B. Single Switched BBE}

A hardware prototype of the single BBE, incorporating 4 PIN diode switches was fabricated, see Fig. 9. By altering the switch states, it is possible to reconfigure the operation of the device between the antenna and filter modes. Each switch is voltage controlled. For this application, a PIN diode from Infineon (BAR50-02V) was employed. This PIN diode is cheap and readily available. Fig. 10 shows the lumped element equivalent circuits for the PIN diode in the ON and OFF states. These equivalent circuits were used within the computer simulations. A biasing circuit was designed and fabricated. The circuit incorporates eight DC blocking inductors manufactured by coilcraft (part number: 0402HP-20N). This inductor has a nominal inductance of $20 \mathrm{nH}$ but its inductance at $2.4 \mathrm{GHz}$ is approximately $27 \mathrm{nH}$ [41]. In addition, an $83 \Omega$ resistor was used, in conjunction with the $9 \mathrm{~V}$ battery, to limit the current flowing through the PIN diode to $100 \mathrm{~mA}$. This prevents damage to the PIN diode and ensures low switch insertion loss in the on-state.

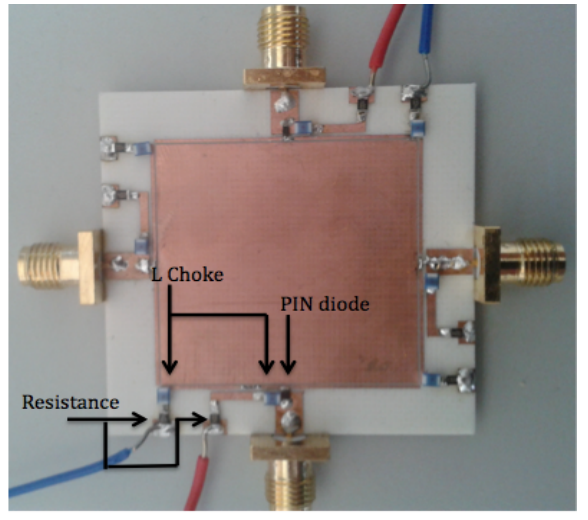

Fig. 9. Single BBE incorporating PIN diode switches.

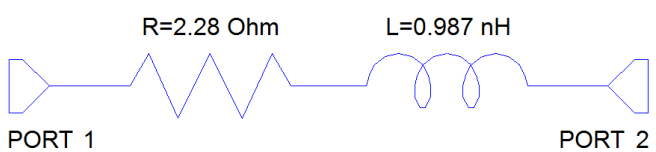

a)

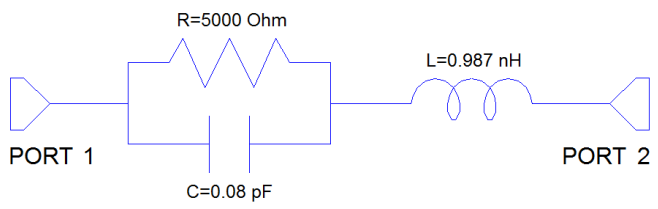

b)

Fig. 10. Lumped element equivalent circuits for the BAR50-02V pin diode: a) on-state, and b) off-state.

Fig. 11 presents the simulated and measured scattering parameters for the single BBE shown in Fig. 9. When the BBE is operated within the filter mode a bandpass response at 2.43 $\mathrm{GHz}$ is obtained. The filter has a measured $-3 \mathrm{~dB}$ transmission bandwidth of $1.76 \%$ (i.e. $42.8 \mathrm{MHz}$ ). When the single $\mathrm{BBE}$ is operated within the antenna mode, it has a resonant frequency of $2.41 \mathrm{GHz}$ and a return loss of around $20 \mathrm{~dB}$. At frequencies around the operating point, the isolation between ports 1,2 , and 3 is better than $-20 \mathrm{~dB}$ and $-30 \mathrm{~dB}$, for the filter and antenna modes, respectively. In general, there is good agreement between the simulation and measurement results. The differences can be attributed to the fabrication tolerance as well as the use of ideal DC biasing components (without parasitics) within the simulations.

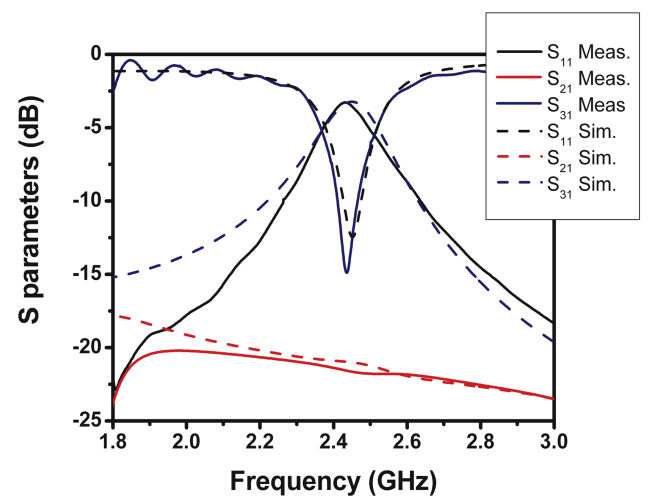

a) 


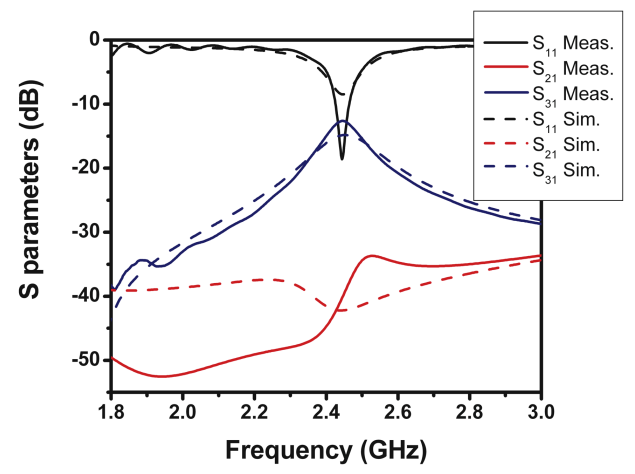

b)

Fig. 11. Scattering parameters pertaining to: a) filter mode, and b) antenna mode.

The performance of the switched single BBE, shown in Fig. 9, is similar to that of the hard-wired prototype, shown in Fig. 5. However, losses introduced by the PIN diode switches have the effect of degrading the performance. The total efficiency of the switched BBE in antenna mode is $76.3 \%$. While, in the filter mode, the insertion loss is $-3.38 \mathrm{~dB}$. The performance of the hard-wired and the switched prototypes are summarized in Table V, allowing easy comparison.

TABLE $\mathrm{V}$

ANTENNA EFFICIENCY AND FILTER LOSSES

\begin{tabular}{ccccc}
\hline \hline Operation & Technology & $\begin{array}{c}\text { Eff. } \\
(\%)\end{array}$ & $\begin{array}{c}\text { IL } \\
(\mathrm{dB})\end{array}$ & $\begin{array}{c}\text { Freq } \\
(\mathrm{GHz})\end{array}$ \\
\hline Filter & Hard-wired & - & 2.79 & 2.41 \\
Filter & Switched & - & 3.38 & 2.43 \\
Antenna & Hard-wired & 83.1 & - & 2.42 \\
Antenna & Switched & 76.3 & - & 2.44 \\
\hline \hline
\end{tabular}

The radiation patterns pertaining to the antenna mode of operation are shown in Fig. 12. These patterns are almost identical to those shown, in Fig. 8 for the hard-wired single BBE, in Section III. A. The switched BBE exhibits a realized gain of $4.49 \mathrm{dBi}$. This is $0.74 \mathrm{~dB}$ lower than that associated with the hard-wired BBE.

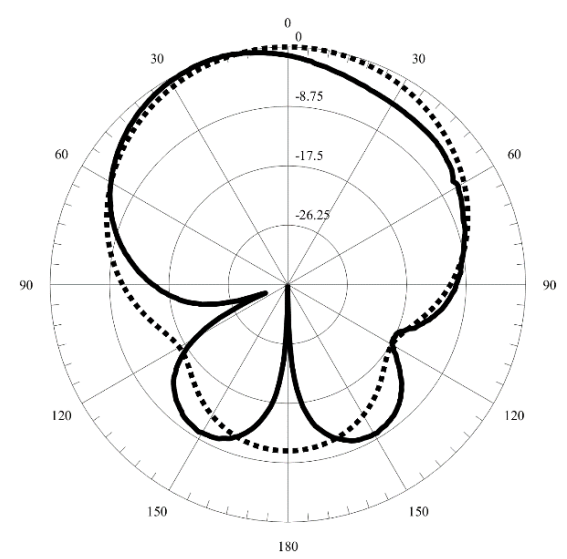

a)

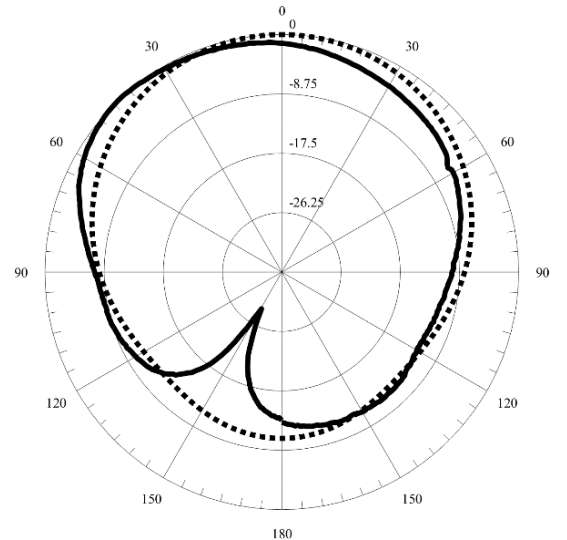

b)

Fig. 12. Radiation patterns: a) E-plane, and b) H-plane. Solid lines and dashed lines represent measured co-polar and simulated co-polar patterns, respectively.

\section{Device Incorporating Three Hard-Wired BBEs}

This subsection of the paper pertains to a device incorporating 3 BBEs. Three hardware prototypes were fabricated, see Fig. 13. These devices are nominally identical but incorporate different hard-wired switch configurations. The three designs are denoted Design 1 to Design 3. Please refer to Fig. 4 for a definition of the port numbers, used here. Design 1 operates in the filter mode between ports 1 and 5. In Designs 2 and 3 the device works in the antenna mode, on ports 3 and 2, respectively. Designs 2 and 3 exhibit different radiation pattern shapes, to be specific the main beam direction is altered.

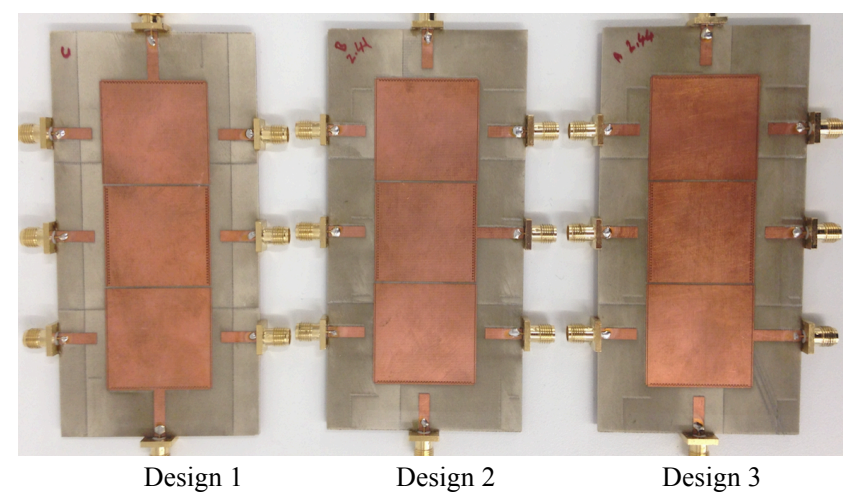

Fig. 13. Hardware prototypes comprising three BBEs.

Fig. 14 shows simulated and measured scattering parameters pertaining to the aforementioned filter and antenna operating modes. A good level of agreement is observed between simulation and measurement. For a 3-pole filter one would expect to observe 3 return loss zeros. Fig. 14 a) shows the scattering-parameters associated with the filter mode of operation between ports 1 and 5. Two of the three zeros are visible in the figure. The third zero is not visible because of the close proximity of two pole locations. This is caused due to the shift of the first return loss zero towards the second one as a consequence of very small changes in some of the 
dimensions of the structure. Those dimensional changes can be attributed to fabrication errors and tolerances. According to the measured results for the filter mode response, the deepest return loss zero occurs at a frequency of $2.44 \mathrm{GHz}$. The measured $10 \mathrm{~dB}$ return loss bandwidth is $6.8 \%$ (i.e. $167 \mathrm{MHz}$ ). The minimum value of filter insertion loss is $4.58 \mathrm{~dB}$ and corresponds to the second return loss zero which is located at a frequency of $2.53 \mathrm{GHz}$.

For the reason mentioned in connection with the filter mode, we would also expect to observe 3 return loss zeros in the response for the antenna mode. Figs. 14 b) and $14 \mathrm{c}$ ) show scattering parameters pertaining to the antenna modes of operation. For both Designs 2 and 3, the main resonance, at around $2.45 \mathrm{GHz}$, can be attributed to the driven element, i.e. the patch that is directly fed by the microstrip line, while the other resonances are associated with the parasitic parches. For Design 2, two measured return loss zeros are visible. The remaining return loss zero is suppressed due to poor impedance matching. Specifically, the real part of the input impedance is much larger than Z0 (i.e. $50 \Omega$ ) at resonance. There are also two measured deep zeros in the return loss curve for Design 3. In all cases, the real part of the input impedance is close to Z0. The transitions in the imaginary part of the input impedance, in the vicinity of the two deep return zeros, indicate that there are in fact three resonances in this area. However, two of those resonances are very close together and so lead to only one unique return loss zero. For the antenna mode, the deepest measured return loss zeros are observed at frequencies of $2.41 \mathrm{GHz}$ and $2.44 \mathrm{GHz}$ for Designs 2 and 3, respectively. The measured return loss values at these frequencies are $11.9 \mathrm{~dB}$ and $20.4 \mathrm{~dB}$, respectively. Moreover, the total efficiency is $81.1 \%$ and $76.9 \%$ for the aforementioned antenna modes. In the antenna mode of operation, it is undesirable for energy to be transferred from port 3 (in Design 2) or port 2 (in Design 3) to any of the unused ports. According to the measurement results the peak level of energy transfer, between those ports, under antenna mode operation is always less than $-25 \mathrm{~dB}$. For the filter mode of operation, the peak level of unintended energy transfer is less than $-35 \mathrm{~dB}$.

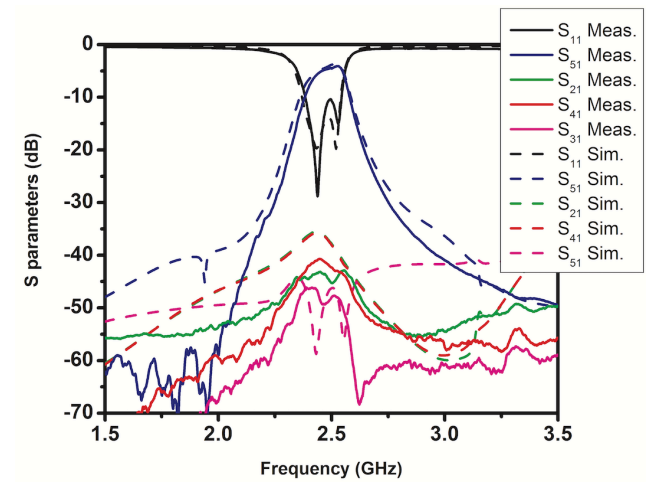

a)

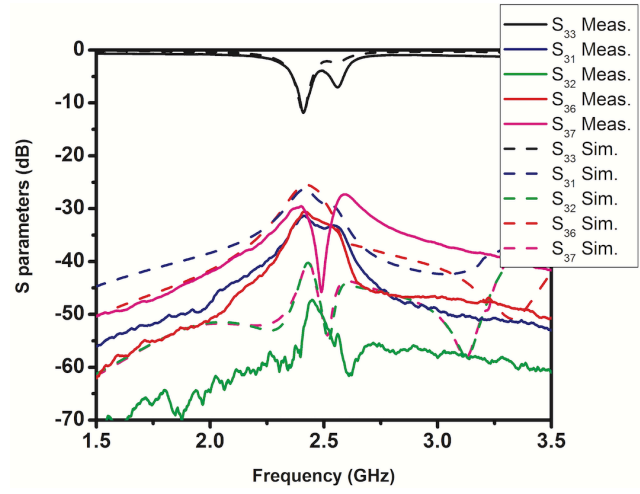

b)

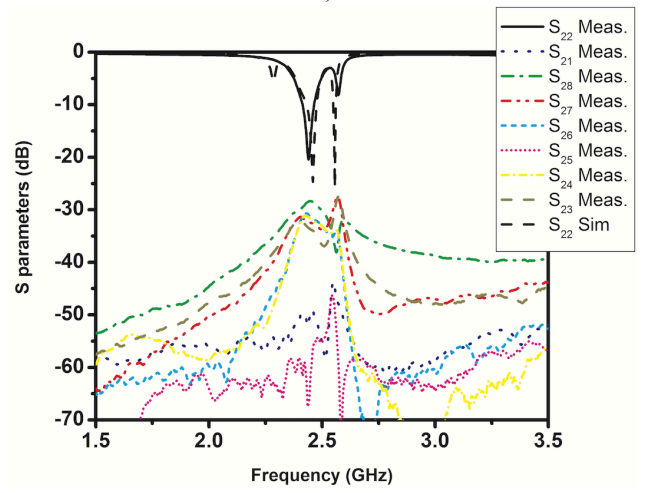

c)

Fig. 14. Scattering parameters for: a) filter mode (Design 1), b) and c) antenna modes (Design 2 and 3).

In addition, the measured radiation patters for Design 2 in the E-plane and H-plane have been obtained, see Fig. 15. In Design 2, port 3 feeds the central patch of the device. This yields a main lobe directed towards boresight (i.e. $0^{\circ}$ ). For Design 2 the simulated H-plane realized gain was $7.86 \mathrm{dBi}$. The realized gain in the E-plane is identical to that in the $\mathrm{H}$ plane. However, the $3 \mathrm{~dB}$ beamwidths differ. The radiation pattern is narrower in the H-plane than in the E-plane. The reason for this is that the patches, on either side of the driven element, act as parasitics, in a manner analogous to a YagiUda antenna. This has the effect of increasing the aperture area and hence gain. The E-plane and H-plane $3 \mathrm{~dB}$ beamwidths were $88.1^{\circ}$ and $51.4^{\circ}$, respectively. It is undesirable for the device to radiate when operating in the filter mode. In order to assess this, radiation patterns, for the filter mode, were obtained through measurement. The E-plane and H-plane gains for Design 1 (filter mode) are approximately $10.18 \mathrm{~dB}$ and $2.88 \mathrm{~dB}$ lower than those associated with Design 2 (antenna mode). The E-plane and H-plane gains for Design 1 (filter mode) are approximately $5.46 \mathrm{~dB}$ and $1.72 \mathrm{~dB}$ lower than those associated with Design 3 (antenna mode). These results indicate good discrimination between filter and antenna modes of operation. It is also clear that the discrimination of the $3 \mathrm{BBE}$ device is improved significantly compared with that of the $1 \mathrm{BBE}$ device. 


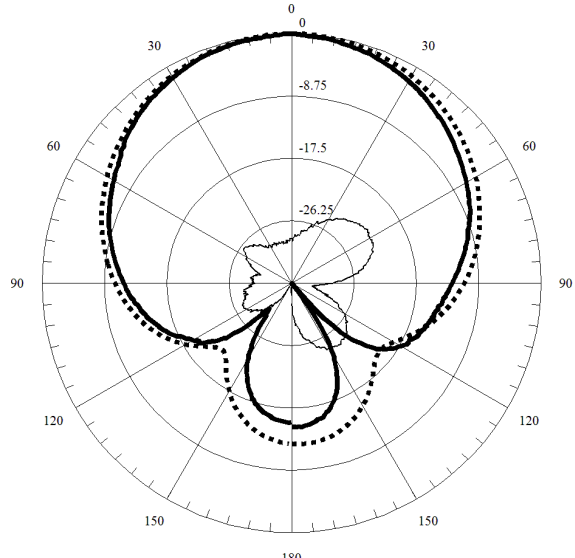

a)

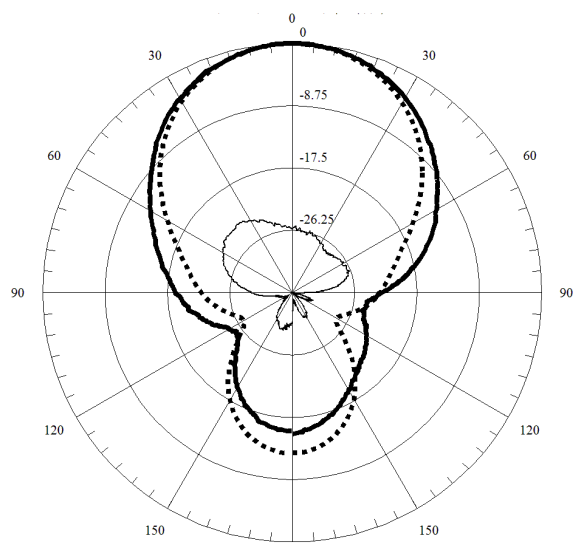

b)

Fig. 15. Radiation patterns for Design 2: a) E-plane, and b) H-plane. Solid line, dashed line, and thin solid line, represent measured co-polar, simulated co-polar, and measured cross-polar, respectively.

Fig. 16 shows the radiation patterns for Design 3. There is good agreement between the pattern shapes obtained through simulation and measurement. For Design 3 the H-plane realized gain was $7.49 \mathrm{dBi}$. The realized gain in the E-plane is identical to that in the H-plane. However, the $3 \mathrm{~dB}$ beamwidths differ. The radiation pattern is narrower in the $\mathrm{H}$ plane than in the E-plane, for the reason explained earlier. The measured main lobe direction is $35^{\circ}$. A second lobe appears in the H-plane at $-42^{\circ}$. The E-plane main lobe gain for Design 3 is $-2.63 \mathrm{dBi}$. For the reason explained above the radiation pattern is once again narrower in the H-plane than in the Eplane. The E-plane pattern is approximately orientated towards the boresight direction, as expected. In all cases, the cross-polar radiation pattern has a much smaller peak amplitude than that of the co-polar radiation pattern (more than $22 \mathrm{~dB}$ lower).

In summary, the device is able to provide filtering action between various different combinations of ports. Altering the choice of input and output ports has the effect of varying the $10 \mathrm{~dB}$ return loss bandwidth of the filter. For example, between ports 1 and 5 we obtain a wider bandwidth and higher selectivity than between ports 3 and 7 (or 2 and 8 or 4 and 6), namely $6.1 \%$ and $1.76 \%$, respectively.

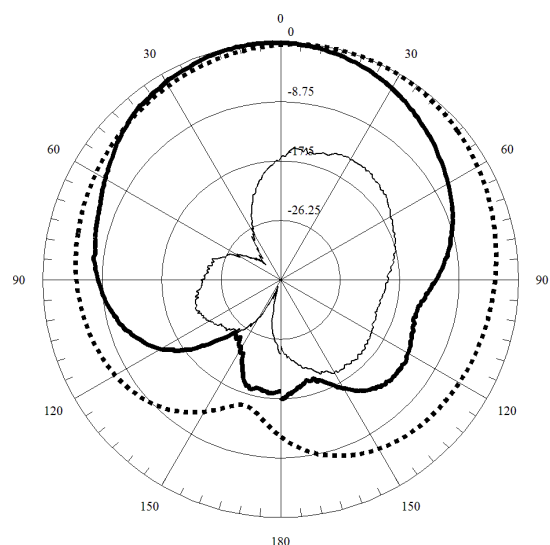

a)

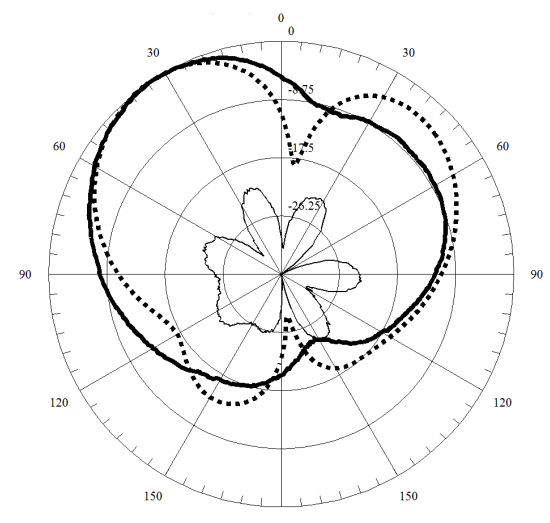

b)

Fig. 16. Radiation patterns for Design 3: a) E-plane, and b) H-plane. Solid line, dashed line, and thin solid line, represent measured co-polar, simulated co-polar, and measured cross-polar, respectively.

In antenna mode operation, the wave polarization and aperture area can also be varied depending on the selection of feeding ports. If port 3 is fed the $3-\mathrm{dB}$ beamwidth is approximately $90^{\circ}$. If ports $2,4,6$, or 8 are fed, the $3-\mathrm{dB}$ beamwidth is approximately $50^{\circ}$.

\section{Device Incorporating Three Switched BBEs}

This subsection of the paper presents a device incorporating three BBEs and PIN diode switches. The device is referred to as Design 4. The switches are inserted into the transmission lines associated with ports 1,2 , and 5 (i.e. switches 1,2 , and $5)$ to enable evaluation of the filter and antenna modes. Fig. 17 shows the fabricated prototype (Design 4). The filter mode is obtained between ports 1 and 5 with switches 1 and 5 in the on-state. The antenna mode is obtained on port 2 with switch 2 in the on-state. Fig. 18 shows the scattering parameters for Design 4 in the filter and antenna modes, respectively. There is reasonable agreement between simulation and measurement. Also, the results are similar to those for the hardwired design (i.e. Designs 1 and 3). Once again one would expect to observe three return loss zeros in the both the filter and antenna mode response. Two of those return loss zeros are 
clearly visible, the third is not visible due to the reasons explained in Section IV.C.

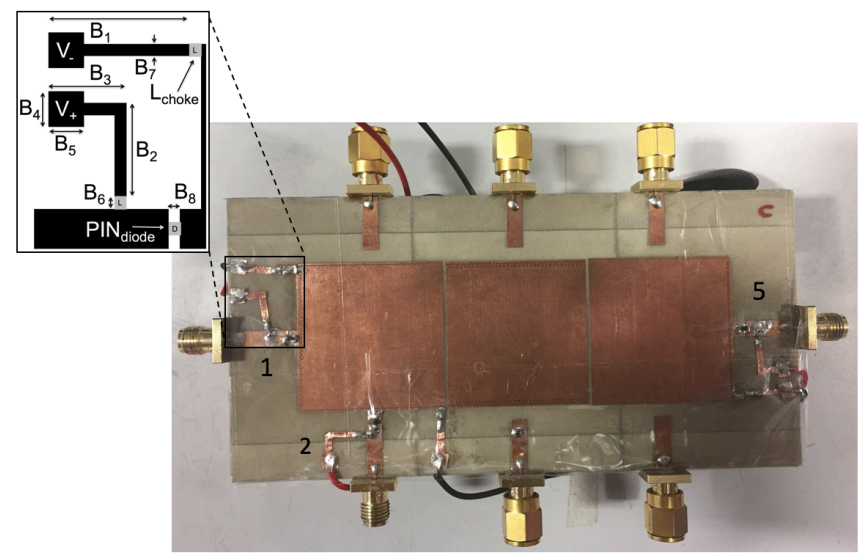

Fig. 17. Fabricated prototype incorporating three switched BBEs. Dimensions (in $\mathrm{mm}$ ) are $\mathrm{B} 1=12, \mathrm{~B} 2=8, \mathrm{~B} 3=6.625, \mathrm{~B} 4=\mathrm{B} 5=3, \mathrm{~B} 6=\mathrm{B} 7=\mathrm{B} 8=1$.

The transmission response from port 1 to port 5 for the filter mode in Design 4 is similar to that for Design 1 indicating that the insertion losses within the PIN diodes are very low. More specifically, minimum insertion loss is $4.8 \mathrm{~dB}$. There is a small observable shift in the resonant frequency of the antenna mode, between measurement and simulation.

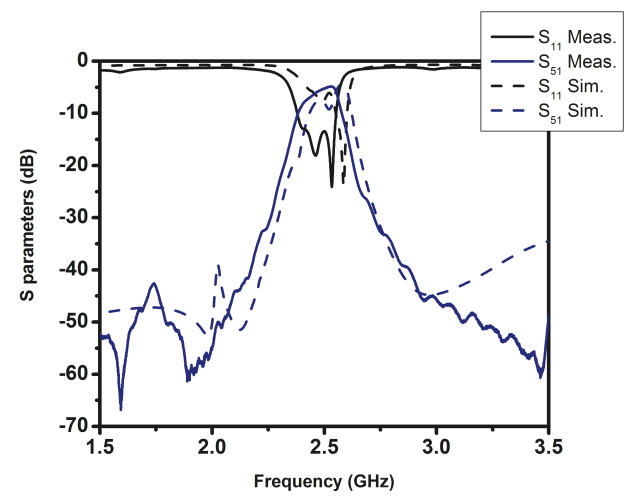

a)

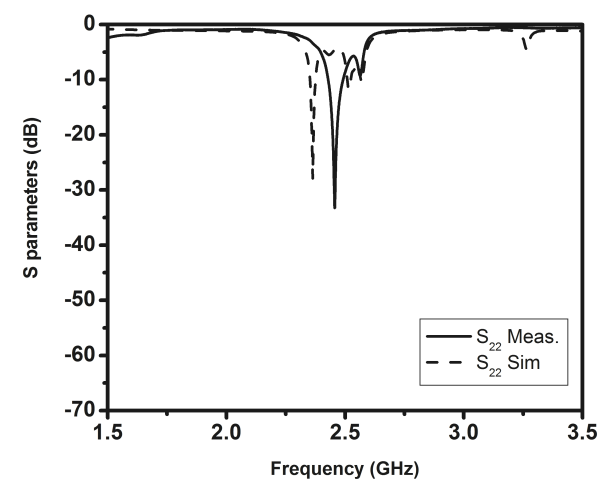

b)

Fig. 18. Scattering parameters for: a) filter mode (Design 4), and b) antenna mode (Design 4).

Finally, Fig. 19 shows the radiation patterns associated with the antenna mode of operation. The E-plane pattern is orientated towards the boresight direction, as expected. The $\mathrm{H}$-plane pattern is tilted towards an angle of approximately $30^{\circ}$. The beamwidth is also narrower in the $\mathrm{H}$-plane, for the reasons explained earlier. For the antenna mode, the simulated $\mathrm{H}$-plane realized gain was $4.9 \mathrm{dBi}$. The realized gain in the Eplane is identical to that in the H-plane. However, the $3 \mathrm{~dB}$ beamwidths differ. Efficiency was found to be around $60 \%$.

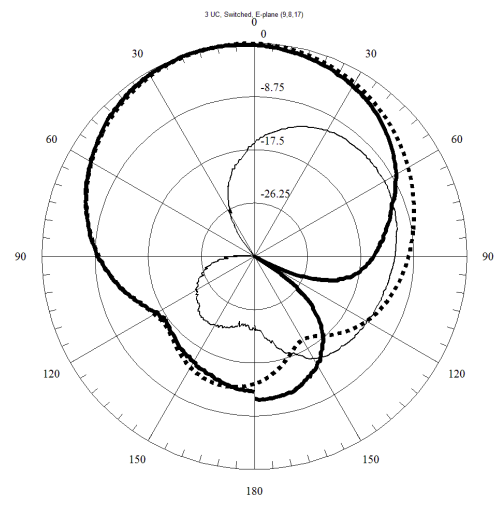

a)

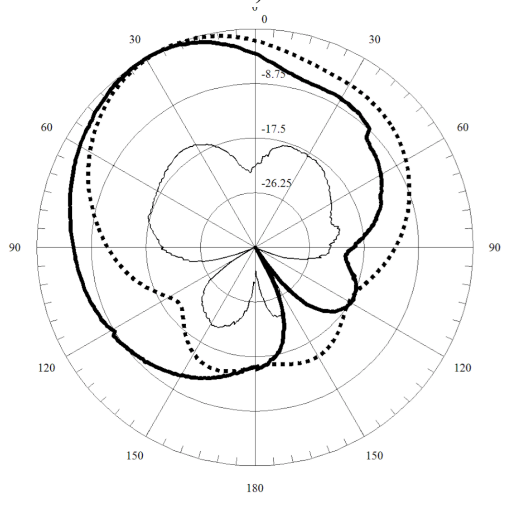

b)

Fig. 19. Radiation patterns for Design 4: a) E-plane, and b) H-plane. Solid line, dashed line, and thin solid line, represent measured co-polar, simulated co-polar, and measured cross-polar, respectively.

It is undesirable for the switched $3 \mathrm{BBE}$ device to radiate when operating in the filter mode. To assess this radiation patterns for the filter mode were obtained through measurement. The H-plane gain, in the filter mode, is approximately $8.84 \mathrm{~dB}$ lower than that associated with the antenna mode, on port 2 . The E-plane gain, in the filter mode, is approximately $7.91 \mathrm{~dB}$ lower than that associated with the antenna mode, on port 2. This indicates good discrimination between filter and antenna mode operation. It is also clear that the discrimination of the $3 \mathrm{BBE}$ device is improved significantly compared with that of the $1 \mathrm{BBE}$ device. It is worthwhile mentioning that the filter and antenna modes can be activated simultaneously or independently. Future work could be carried out in this exciting new area. For example, the characteristics and control of device operation mode, bandwidth, selectivity, polarization and radiating area could be improved and extended to yield new programmable multifunctional microwave devices with higher numbers of 
building blocks. Moreover, new properties could be added, e.g. frequency of operation could be modified including new building blocks with differing sizes.

\section{CONCLUSION}

This paper presents a building block element (BBE) for a multi-functional microwave circuit. The device/circuit can be electronically reconfigured to operate either as a filter or an antenna. The BBE is based around a single square microstrip patch resonator. Reconfiguration is achieved by varying the state of microwave switches, located within the feed lines. A parametric study was conducted in order to examine the effect of the substrate parameters on the performance of the device/circuit within the antenna and filter mode of operation. A hardware prototype for the BBE was constructed. The prototype incorporates hard-wired switches. Measured results show that the devices exhibit good performance in terms of insertion loss and efficiency in both the filter and antenna mode of operation. In addition, a number of hardware prototypes for devices comprising three BBEs were also designed and fabricated. Some of those incorporated hardwired switches and others incorporated PIN diodes. The results indicate that the device is capable of yielding good performance within both filter and antenna mode. The use of programmable multi-functional microwave devices offers a new paradigm for real time reconfigurable systems and can be envisioned to have a wide range of applications.

\section{REFERENCES}

[1] J.-S. Hong, "Reconfigurable planar filters," IEEE Microwave Magazine, vol. 10, no. 6, pp. 73-83, 2009.

[2] P. Wong and I.C. Hunter, "Electronically Reconfigurable Microwave Bandpass Filter," IEEE Trans. Microwave Theory and Tech., vol.5 7, no. 12, pp. 3070-79, 2009.

[3] B. Yassini, Y. Ming and B. Keats, "A Ka-Band Fully Tunable Cavity Filter," Trans. IEEE Microwave Theory and Tech., vol. 60, no. 12, pp. 4002-12, 2012.

[4] K. Rabbi and D. Budimir, "Highly Selective Reconfigurable Filter for UWB Systems," IEEE Microwave and Wireless Components Lett., vol. 24, no. 3, pp. 146-8, 2014.

[5] A. L. Borja, J. Carbonell, J. D. Martinez, V. E. Boria and D. Lippens, "A Controllable Bandwidth Filter Using Varactor-Loaded Metamaterial-Inspired Transmission Lines," IEEE Antennas and Wireless Prop. Lett., vol. 10, no., pp. 1575-78, 2011.

[6] A. Miller and J.-S. Hong, "Reconfigurable cascaded coupled line filter with four distinct bandwidth states," IET Microwaves, Antennas and Prop., vol. 5, no. 14, pp. 1730-37, 2011.

[7] A. Miller, and J. Hong, "Cascaded Coupled Line Filter With Reconfigurable Bandwidths Using LCP Multilayer Circuit Technology," IEEE Trans. Microwave Theory and Tech., vol. 60, no. 6, pp. 1577-86, 2012.

[8] A. Contreras, M. Ribó, L. Pradell, J. Casals-Terré, F. Giacomozzi and J. Iannacci, "K-band RF-MEMS uniplanar reconfigurable-bandwidth bandpass filter using multimodal immittance inverters," Electronics Lett., vol. 49, no. 11, pp. 704-6, 2013.

[9] K. Rabbi, L. Athukorala, C. Panagamuwa, J. C. Vardaxoglou, D. Budimir, "Compact UWB bandpass filter with reconfigurable notched band," Electronics Lett., vol. 49, no. 11, pp. 709-11, 2013.

[10] C. Arnold, J. Parlebas and T. Zwick, "Reconfigurable Waveguide Filter with Variable Bandwidth and Center Frequency," IEEE Trans. Microwave Theory and Tech., vol. 62, no. 8, pp. 1663-1670, 2014.

[11] W. Zhengpeng, J. Kelly, P. Hall, A. Borja, et al, "Reconfigurable Parallel Coupled Band Notch Resonator with Wide Tuning Range," IEEE Trans. Ind. Electr., vol. 61, no. 11, pp. 6316-26, 2014.
[12] E. J. Naglich, J. Lee, D. Peroulis and W. J. Chappell, "Switchless Tunable Bandstop-to-All-Pass Reconfigurable Filter," IEEE Trans. Microwave Theory and Tech., vol. 60, no. 5, pp. 1258-65, 2012.

[13] A. Abunjaileh and I. Hunter, "Tunable bandpass and bandstop filters based on dual-band combline structures," IEEE Trans. Microwave Theory and Tech., vol. 58, no. 12, pp. 3710-19, 2010.

[14] M. F. Karim, A.-Q. Liu, A. Alphones and A. Yu, "A Reconfigurable Micromachined Switching Filter Using Periodic Structures," IEEE Trans. Microwave Theory and Tech., vol. 55, no. 6, pp. 1154-62, 2007.

[15] N. Behdad and K. Sarabandi, "Dual-band reconfigurable antenna with a very wide tunability range," IEEE Trans. Antennas and Prop., vol. 54, no. 2 , pp. 409-16, 2006.

[16] Y. Tawk, J. Costantine, K. Avery and C. G. Christodoulou, "Implementation of a Cognitive Radio Front-End Using Rotatable Controlled Reconfigurable Antennas," IEEE Trans. Antennas and Prop., vol. 59, no. 5, pp. 1773-78, 2011.

[17] J. Costantine, Y. Tawk and C. G. Christodoulou, "Motion-Activated Reconfigurable and Cognitive Radio Antenna Systems," IEEE Antennas and Wireless Prop. Lett., vol. 12, pp. 1114-17, 2013.

[18] B. Mun; C. Jung, M.-J. Park and B. Lee, "A Compact FrequencyReconfigurable Multiband LTE MIMO Antenna for Laptop Applications," IEEE Antennas and Wireless Prop. Lett., vol. 13, pp. 1389-92, 2014.

[19] C. Sun, H. Zheng, L. Zhang and Y. Liu, "A Compact FrequencyReconfigurable Patch Antenna for Beidou (COMPASS) Navigation System," IEEE Ant. and Wireless Prop. Lett., vol. 13, pp. 967-70, 2014.

[20] A. L. Borja, A. Belenguer, J. Cascon and J. R. Kelly, "A Reconfigurable Passive UHF Reader Loop Antenna for Near-Field and Far-Field RFID Applications," IEEE Antennas and Wireless Prop. Lett., vol. 11, pp. 580-83, 2012.

[21] Y.-Y. Bai, S. Xiao, C. Liu, X. Shuai et al, "Design of Pattern Reconfigurable Antennas Based on a Two-Element Dipole Array Model," IEEE Trans. Ant. and Prop., vol. 61, no. 9, pp. 4867-71, 2013.

[22] Z. Li, E. Ahmed, A. M. Eltawil and B. A. Cetiner, "A Beam-Steering Reconfigurable Antenna for WLAN Applications," IEEE Trans. on Antennas and Prop., vol. 63, no. 1, pp. 24-32, 2015.

[23] S. Raman, P. Mohanan, N. Timmons and J. Morrison, "Microstrip-Fed Pattern- and Polarization- Reconfigurable Compact Truncated Monopole Antenna," IEEE Antennas and Wireless Prop. Lett., vol. 12, pp. 710-13, 2013.

[24] H. L. Zhu, S. W. Cheung, X. H. Liu, and T. I. Yuk, "Design of Polarization Reconfigurable Antenna Using Metasurface," IEEE Trans. on Antennas and Prop., vol. 62, no. 6, pp. 2891-98, 2014.

[25] B. Wu, M. Okoniewski and C. Hayden, "A Pneumatically Controlled Reconfigurable Antenna With Three States of Polarization," IEEE Trans. Antennas and Prop., vol. 62, no. 11, pp. 5474-84, 2014.

[26] C. Bozler et al., "MEMS microswitch arrays for reconfigurable distributed microwave components," 2000 IEEE MTT-S International Microwave Symposium Digest (Cat. No.00CH37017), Boston, MA, USA, 2000, pp. 153-56 vol.1.

[27] G. C. Tavik et al., "The advanced multifunction RF concept," in IEEE Trans. on Microwave Theory and Tech., vol. 53, no. 3, pp. 1009-20, March 2005.

[28] A. Ouacha, and C. Samuelsson "Programmable Microwave Circuit," Patent PCT/SE2006/000408, 12/10/2006.

[29] C. Samuelsson, A. Ouacha, N. Ahsan and T. Boman, "Programmable microwave function array, PROMFA," Microwave Conference APMC 2006, Asia-Pacific, 12-15 Dec., pp. 1787-90, 2006.

[30] N. Ahsan, A. Ouacha, C. Samuelsson and T. Boman, "Applications of Programmable Microwave Function Array (PROMFA)," 18th European Conference on Circuit Theory and Design, Seville, 2007, pp. 164-67.

[31] R. Malmqvist, A. Ouacha and R. Erickson, "Multi-Band and Reconfigurable Front-Ends for Flexible and Multi-Functional RF Systems," Asia-Pacific Microwave Conference, Bangkok, 2007, pp. 14.

[32] L. Rabieirad, E. J. Martinez and S. Mohammadi, "Mask Programmable CMOS Transistor Arrays for Wideband RF Integrated Circuits," in IEEE Trans. Microwave Theory and Tech., vol. 57, no. 6, pp. 143946, June 2009.

[33] S. Tricarico, F. Bilotti and L. Vegni, "Multi-functional dipole antennas based on artificial magnetic metamaterials," in IET Microwaves, Antennas \& Prop., vol. 4, no. 8, pp. 1026-38, Aug. 2010.

[34] L. Rabieirad, E. J. Martinez and S. Mohammadi, "An Integration Technology for RF and Microwave Circuits Based on Interconnect 
Programming," in IEEE Trans. Advanced Packaging, vol. 33, no. 2, pp. 362-69, May 2010.

[35] J. R. Kelly and A. L. Borja, "Hardware block for use in programmable microwave function arrays," Electronics Lett., vol. 50, no. 15, pp. 107677, 2014.

[36] J. R. Kelly and A. L. Borja, "Microwave multi-tool," Electronics Lett., vol. 50, no. 15, pp. 1035-35, 2014.

[37] J. R. Kelly and A. L. Borja, "Reconfigurable microwave circuit based on three triangular microstrip patches", IEEE International Symposium on Antennas and Prop. \& USNC/URSI National Radio Science Meeting, Vancouver, Canada, 19-24 July, 2015.

[38] A. L. Borja and J. R. Kelly, "Reconfigurable microwave circuit based on a single triangular microstrip patch", IEEE International Symposium on Antennas and Prop. \& USNC/URSI National Radio Science Meeting, Vancouver, Canada, 19-24 July, 2015.

[39] J.-S. Hong and M. Lancaster, Microstrip Filters for RF/Microwave Applications. John Wiley \& Sons, Inc., 2001.

[40] C. A. Balanis, Antenna Theory: Analysis and Design. John Wiley \& Sons, Inc., 2005.

[41] http://www.coilcraft.com/apps/finder/rffinder.cfm

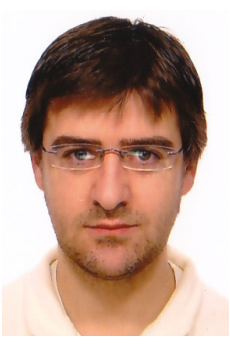

Alejandro L. Borja received the M.Sc. degree in telecommunication engineering and the Ph.D. degree from the Universidad Politecnica de Valencia, Valencia, Spain, in 2004 and 2009, respectively. From 2005 to 2006, he was with the University of Birmingham, Birmingham, U.K. From 2007 to 2008, he was with the Universite de Lille 1, Lille, France. Since 2009, he has been with the Universidad de Castilla-La Mancha, Spain, where he is an Assistant Lecturer. He has published more than 50 papers in peer-reviewed international journals and conference proceedings, and frequently acts as a reviewer for several technical publications. His research interests include EM metamaterials, substrate integrate waveguide, and reconfigurable devices and their applications in microwave and millimetric bands.

Dr. Borja was the recipient of the 2008 CST short paper award.

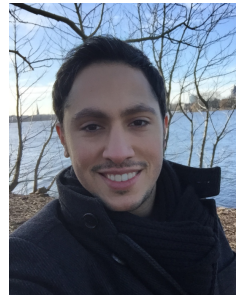

Yasin Kabiri received the MEng. Degree in electronics and communication Engineering from the University of Birmingham with first class honour, Birmingham, U.K., in 2012. In 2015, he achieved his $\mathrm{PhD}$ degree at the School of Electronic and Electrical Engineering, University of Birmingham, Birmingham, U.K. During his PhD he has developed an approach called Injection Matching Theory (IMT) which can be used for making small, wide band, reconfigurable antennas with high efficiency. His current research interests are in the areas of RF and microwave, Electrically small antenna, reconfigurable antennas, active antennas, microwave filters and broadband and multiband antennas. He is now working as a research fellow in $5 \mathrm{G}$ innovation centre with focus on $5 \mathrm{G}$ antennas.

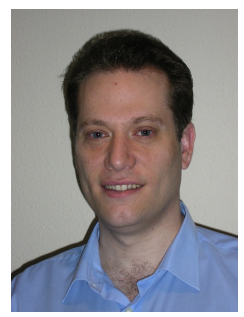

Angel Belenguer (M'04-SM'14) received his degree in telecommunications engineering from the Universidad Polite cnica de Valencia (UPV), Spain, in 2000, and his Ph.D. degree, also from the UPV, in 2009. He joined the Universidad de Castilla-La Mancha in 2000, where he is now Profesor Titular de Universidad in the Departamento de Ingenieria Electrica, Electronica, Automatica y Comunicaciones. He has authored or co-authored more than 50 papers in peer-reviewed international journals and confer- ence proceedings and frequently acts as a reviewer for several international technical publications. His research interests include methods in the frequency domain for the full-wave analysis of open-space and guided multiple scattering problems, the application of accelerated solvers or solving strategies (like grouping) to new problems or structures, EM metamaterials, and Substrate Integrated Waveguide (SIW) devices and their applications.

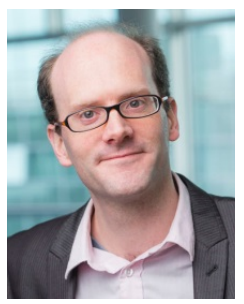

James R. Kelly (M'10) received the Master's degree in electronic and electrical engineering and the Ph.D. degree in microwave filters from Loughborough University, U.K., in 2002 and 2007, respectively.

From 2007 to 2012 he worked as a research fellow/associate at Loughborough University, as well as the Universities of Birmingham, Durham, and Sheffield. In 2009, he launched a small company which provides technical training on microwave antenna design (Microwave and RF Solutions). During 2001 and 2012, respectively he worked within the Rolls-Royce Strategic Research Centre and at Airbus Defence and Space Ltd. From 2012 to 2013 he was a Lecturer at Anglia Ruskin University, Cambridge, U.K.. In 2013 he joined the Institute for Communication Systems (ICS) at the University of Surrey, U.K. where he is employed as a Lecturer in Microwave Antennas.

Dr Kelly has published almost 80 academic papers in peer-reviewed journals and conference proceedings. He holds a European patent on reconfigurable antennas. He is a member of the Institution of Engineering and Technology (IET), the Institute of Electrical and Electronics Engineers (IEEE), and the IEEE Industrial Electronics Society. His primary research focus is reconfigurable antennas. His also has experience of working on small antennas for portable device applications, UWB antennas, planar microwave filters, metamaterials, and material characterisation. 